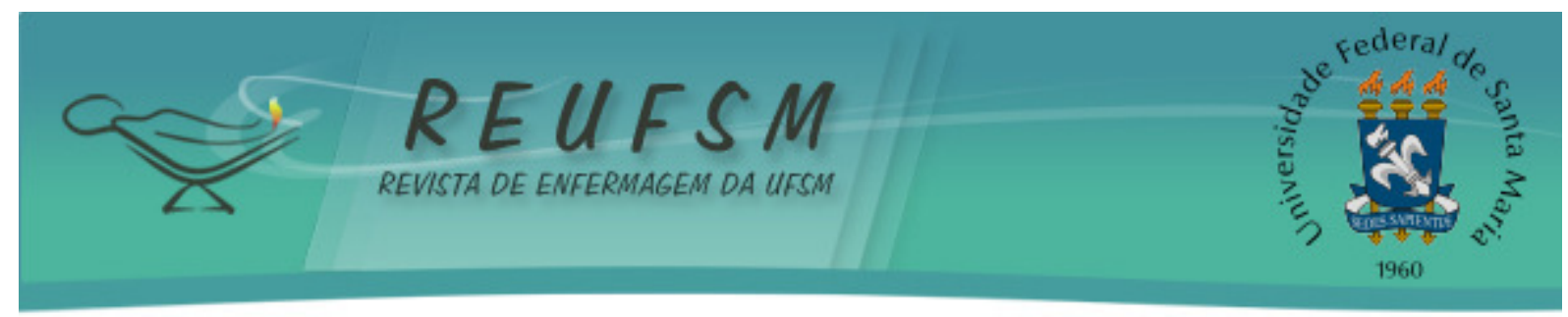

ARTIGO DE REFLEXÃO

\title{
HERMENÊUTICA E O CUIDADO DE ENFERMAGEM AO PACIENTE PORTADOR DE FERIDA TUMORAL: UMA REFLEXÃO FILOSÓFICA
}

\author{
HERMENEUTICS AND NURSING CARE TO PATIENTS WITH A TUMOR WOUND: A \\ PHILOSOPHICAL REFLECTION
}

\section{HERMENÉUTICA Y CUIDADOS DE ENFERMERÍA AL PACIENTE CON HERIDAS TUMORALES: UNA REFLEXIÓN FILOSÓFICA}

\author{
Patrícia Lima Queiroz ${ }^{1}$ \\ Janaína de Jesus Castro Câmara ${ }^{2}$ \\ Santana de Maria Alves de Sousa ${ }^{3}$ \\ Helder Machado Passos ${ }^{4}$
}

Doi: $10.5902 / 2179769218127$

RESUMO: Objetivo: refletir sobre o saber e fazer do cuidado de enfermagem ao paciente portador de ferida tumoral, sob a hermenêutica filosófica de Gadamer. Método: trata-se de um estudo reflexivo. Resultados: a inter-relação dinâmica entre o conhecimento científico e o empírico é desejável e até necessária. A filosofia revela que a prática do fazer e do agir de forma eficiente e eficaz, correlaciona-se com a técnica, além de apresentar, o agravamento da relação entre a teoria (saber) e a práxis (fazer) sob as condições da ciência moderna. 0 enfermeiro, muitas vezes, cuida do paciente portador de ferida neoplásica, a partir de vivências e experiências profissionais, expressando-se por um caráter dialógico. O diálogo é o dispositivo evidente no pensamento hermenêutico de Gadamer. Conclusão: o pensamento hermenêutico de Gadamer e a fundamentação filosófica do conhecimento trazem contribuições para a relação de cuidado entre o enfermeiro e o paciente portador de ferida tumoral.

Descritores: Filosofia; Enfermagem; Neoplasias.

ABSTRACT: Aim: to reflect on the knowledge and practice of nursing care to patients with a tumor wound, under the philosophical hermeneutics of Gadamer. Method: this is a reflective study. Results: the dynamic interplay between scientific knowledge and the empirical is desirable and even necessary. The philosophy reveals that the practice of doing and acting efficiently and effectively correlates with the technique, and presents the relationship deterioration between theory (knowledge) and practice (doing) under the conditions of modern science. The nurse often takes care of neoplastic wound of a patient from life experiences and professional experiences, being expressed by a dialogical character. Dialogue is the obvious device in the hermeneutical thought of Gadamer. Conclusion: the hermeneutical thought of Gadamer and philosophical foundation of

\footnotetext{
${ }^{1}$ Enfermeira. Mestranda em Enfermagem. Universidade Federal do Maranhão. Docente da Faculdade Santa Terezinha - CEST. Bolsista CAPES. São Luís, Maranhão, Brasil. E-mail: enfpatriciaqueiroz@gmail.com

${ }^{2}$ Enfermeira. Mestranda em Enfermagem. Universidade Federal do Maranhão. Enfermeira Assistencial do Hospital Universitário da Universidade Federal do Maranhão. São Luís, Maranhão, Brasil. E-mail: janaicamara@gmail.com

${ }^{3}$ Enfermeira. Doutora em Ciências Sociais: Antropologia pela PUC-SP. Professora Adjunta do Departamento de Enfermagem e do Programa de Pós-Graduação em Enfermagem da Universidade Federal do Maranhão. São Luís, Maranhão, Brasil. E-mail: santanasousa@uol.com.br

${ }^{4}$ Filósofo. Doutor em Filosofia pela Universidade de São Paulo-USP. Professor Adjunto do Departamento de Filosofia e Professor Colaborador do Programa de Pós-Graduação em Enfermagem da Universidade Federal do Maranhão. E-mail: passos_helder@yahoo.com.br
} 


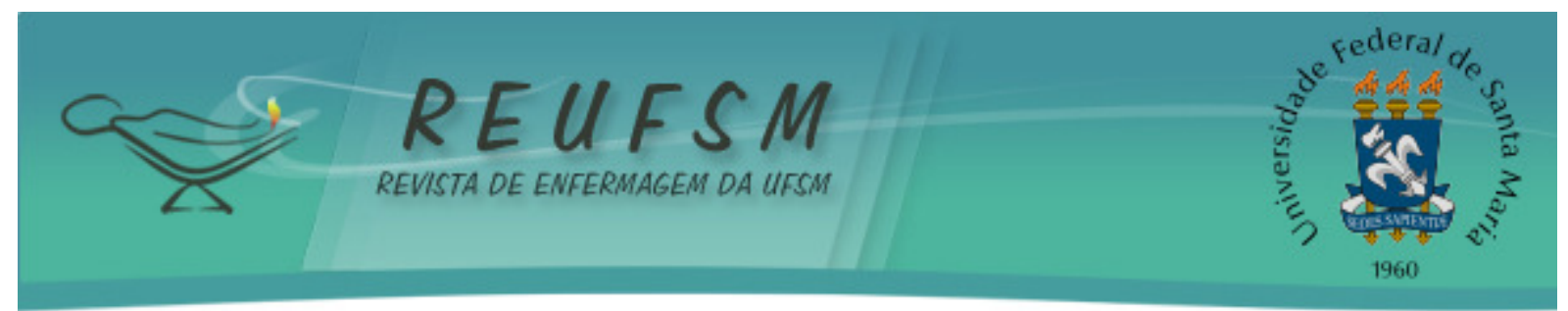

knowledge bring contributions to the care relationship between nurse and patient with tumor wound.

Descriptors:Philosophy; Nursing; Neoplasms.

RESUMEN: Objetivo: reflexionar sobre el conocimiento y la práctica de los cuidados de enfermería a pacientes con heridas tumorales, bajo la filosofía de Gadamer. Método: estudio reflexivo. Resultados: la interacción dinámica entre el conocimiento científico y lo empírico es deseable y necesaria. La filosofía revela que la práctica de hacer y de actuar con eficiencia y eficacia se correlaciona con la técnica, y además, presenta el deterioro de la relación entre la teoría (conocimiento) y la práctica (hacer) en las condiciones de la ciencia moderna. La enfermera a menudo se ocupa de la herida neoplásica de un paciente a partir de experiencias de vida y profesionales, expresándose por un carácter dialógico. El diálogo es un dispositivo evidente en el pensamiento hermenéutico de Gadamer. Conclusión: la hermenéutica de Gadamer y el fundamento filosófico del conocimiento contribuyen para la relación asistencial entre enfermera y paciente con herida tumoral.

Descriptores: Filosofía; Enfermería; Neoplasias.

\section{INTRODUÇÃO}

Gadamer, filósofo alemão, humano e ético, teve seus pensamentos e obras influenciados por outros filósofos como Platão, Aristóteles, Hegel, Heidegger, Nietszche, entre outros, entende que a linguagem revela e serve para avaliar devidamente, por meio da hermenêutica, a dimensão simbólica dos discursos dos sujeitos. A hermenêutica não é só uma simples teoria da arte de compreensão e interpretação, é algo a mais, encontra-se próxima da filosofia prática, tendo que responder pelo caráter metodológico daquilo que ela faz compreender.'

A história de vida de cada paciente ou pessoa envolvida é de extrema importância para se interpretar o processo social, na medida em que se consideram as experiências subjetivas como dados importantes que falam além e por meio delas. A observação empírica e a reflexão permitem ver diversos sujeitos sociais apresentarem respostas e manifestações variadas de comportamento, quando expostos a fatores conflitantes, segundo o seu grau de responsabilidade. ${ }^{2}$

0 cuidado ao paciente portador de ferida tumoral reflete uma realidade complexa de interação entre aspectos físicos, psicológicos, sociais e ambientais da condição humana e de atribuições de significados. ${ }^{3}$ Dessa forma, surge o problema do saber e do fazer no cuidado de enfermagem ao portador de ferida tumoral, visto que se apresenta por meio de uma relação conflitante entre o ser que cuida, dotado de conhecimento e consciência, muitas vezes com propósito de diminuir o sofrimento do outro, e o ser que é cuidado, esse em grande parte carregado por uma consciência esperançosa e curativa sobre os cuidados a serem recebidos.

Muitas vezes, ao paciente portador de ferida tumoral, é imposto cuidado paliativo, por não ter um prognóstico de cura, restringindo-lhe ao controle de sinais e sintomas para o reequilíbrio da sua qualidade de vida o que, de certa forma, gera uma relação conflituosa e problemática entre o enfermeiro cuidador e o paciente. ${ }^{4}$

A partir do exposto, questionou-se: qual a relação da hermenêutica filosófica de Gadamer e o cuidado de enfermagem ao paciente portador de ferida tumoral? Dessa forma, objetivou-se refletir sobre o saber e fazer do cuidado de enfermagem ao paciente portador de ferida tumoral, sob a hermenêutica filosófica de Gadamer, a fim de compreender a experiência vivenciada pelos sujeitos, quais sejam, enfermeiro e paciente. 


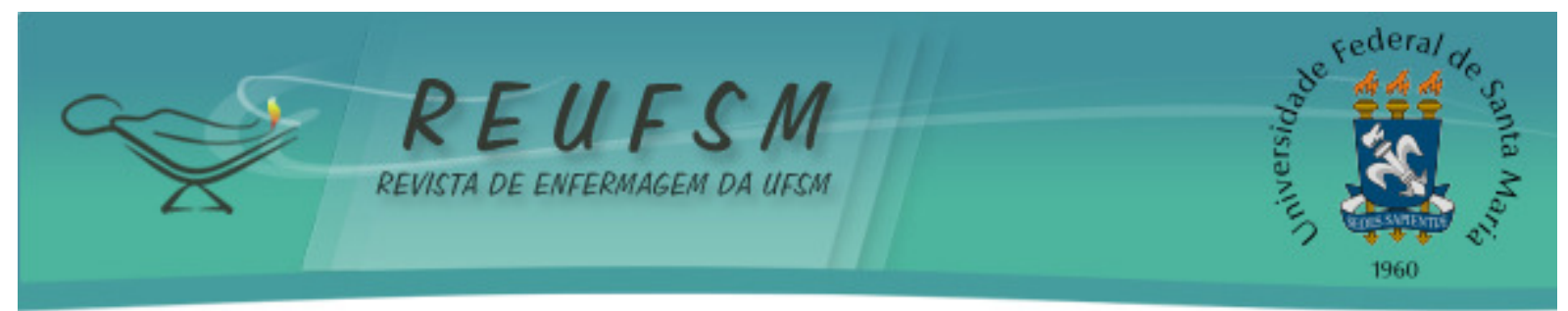

Assim, acreditao-se que, a partir dessa reflexão, seja possível traçar planos de cuidados específicos, coerentes e dialógicos à qualidade de vida desses pacientes.

\section{MÉTODO}

Trata-se de uma reflexão teórica realizada sob a luz da Hermenêutica filosófica de Gadamer e o cuidado de enfermagem ao portador de ferida tumoral. A estratégia de identificação e seleção dos estudos foi a busca de publicações indexadas na Base de Dados de Enfermagem (BDENF), no mês de agosto de 2014.

Foram adotados os seguintes critérios para seleção dos estudos: artigos, teses e monografias com resumos e textos completos disponíveis online; aqueles publicados no idioma português, entre 2005 e 2014. O recurso utilizado na pesquisa foi a expressão "termo exato", associada aos descritores controlados, presentes nos Descritores em Ciências da Saúde/Medical SubjectHeadings (DeCS/MeSH): filosofia, enfermagem e neoplasias, e na obra do filósofo intitulada $O$ caráter oculto da Saúde. ${ }^{2}$

Do material obtido, 25 estudos, procedeu-se à leitura minuciosa de cada publicação, destacando aqueles que responderam ao objetivo proposto por este estudo, a fim de organizar e sustentar a reflexão. Assim, seguindo os critérios de inclusão, 12 publicações científicas foram selecionadas para reflexão deste artigo, além da obra do filósofo intitulada $O$ Caráter Oculto da Saúde, os quais são referenciadas no presente texto por meio de quatro categorias, tais como: fundamentação filosófica sobre saber e práxis; práxis no cuidado de enfermagem; cuidado de enfermagem ao portador de ferida tumoral; hermenêutica de Gadamer e o cuidado de enfermagem.

\section{RESULTADOS E DISCUSSÃO}

\section{Fundamentação filosófica sobre saber e práxis}

O filósofo Kant expressava que todo o conhecimento começa pela experiência. Disse ainda, que isso é o todo que se constitui dos crescentes resultados obtidos em contínuo progresso pela pesquisa da "ciência". No entanto, há o saber acumulado pela experiência, por meio da chamada práxis, não podendo ser entendida como uma simples prática, mas como a união dialética da teoria e da ação moral, em que a razão (teoria) determina o modo como os homens agem, e a ação humana (prática), é projetada, refletida, consciente e racionalizada. 0 saber somente se torna experiência, quando ele passa a integrar a consciência prática daquele que age. Decerto, toda consciência e saber acumulado pela experiência, por meio da práxis, não pode ser desconsiderada pela ciência. ${ }^{5}$

Assim, práxis é representada por escolhas diante de possibilidades. Essas possibilidades pertencem à constituição básica da práxis humana, a qual sempre formou a ideia que o poder e o saber humanos não são adquiridos somente por meio do aprendizado e da experiência. Trata-se da emancipação dos meios para tornarem-se o instrumento, o que potencializa a capacidade de aprendizagem humana e transmite seu ser-capaz-defazer por meio das gerações. ${ }^{1}$

Desse modo, refletir o saber/fazer, que resulta em práxis, remete a fundamentar o conhecimento empírico e o científico. O conhecimento científico, como aquele que constrói verdades apoiadas na aproximação de premissas teóricas, com observações sistematizadas e reiteradas de um fenômeno controlado. Enquanto que o conhecimento empírico, adquirido empiricamente pelo meio, revela experiências particulares, não sistematizadas, que levam a uma confiança no agir correto e seguro. A inter-relação 


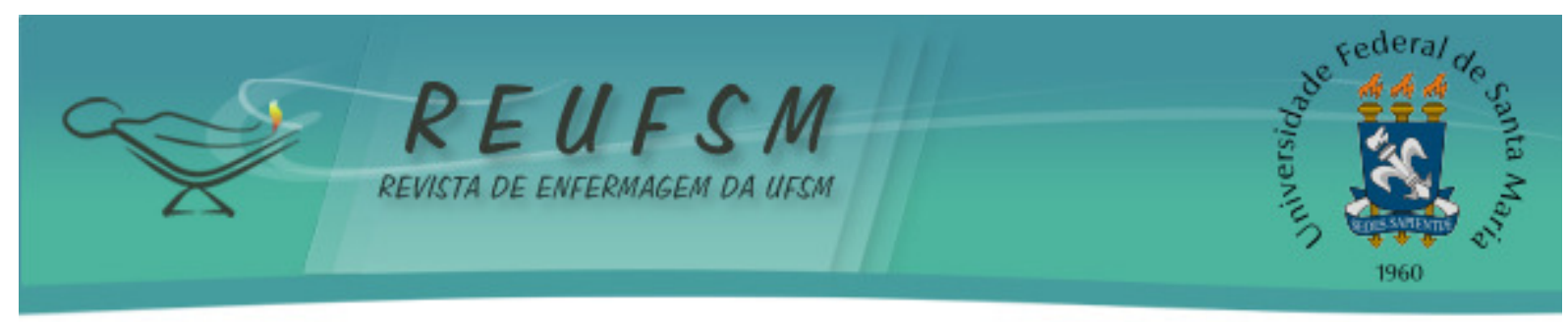

dinâmica entre esses dois conhecimentos é desejável e até necessária para que seja possível questionar verdades, reiterá-las ou refutá-las para refinar os conceitos. A práxis humana é o próprio ser humano em todas as dimensões e como tal, não pode ser seccionada. ${ }^{6}$

$\mathrm{Na}$ experiência da enfermagem, existem duas racionalidades: 0 saber/conhecimento e a práxis, que se referem ao fazer que envolve todo o processo de cuidar em enfermagem. Esse saber possibilita o fazer na perspectiva da ação, por meio da competência, habilidade, persistência, paciência e disponibilidade para uma prática consciente e intuitiva. ${ }^{7}$ Assim,torna-se importante compreender a configuração das práticas e dos saberes manifestados pelas singularidades dos sujeitos envolvidos, visto que as características das singularidades contêm um conjunto das determinações da totalidade. $^{2}$

\section{Práxis no cuidado de enfermagem}

No final do século $X X$, a enfermagem superou as limitações do modelo biomédico tradicional da ciência mecanicista dominante na atenção à saúde. Fez emergir um cuidado mais subjetivo, com significado pessoal que, em meio as diversidades das situações do cotidiano, passou a valorizar o estar junto com o outro, o buscar conhecer o outro com suas diferenças culturais e sociais. ${ }^{5}$

A práxis de enfermagem constitui-se pela utilização dos saberes construídos e reconstruídos dia a dia no processo de reflexão-ação, prática em movimento e teoria em ação.Essa práxis, expressa pela participação do caminho natural em que o homem pode exprimir sua tendência inata de realizar, fazer coisas, afirmar a si mesmo e dominar a natureza e o mundo. A busca por essa participação deve ser contínua e implica envolvimento, compromisso, troca e compartilhamento. Assim, quando o paciente é envolvido no processo de cuidar, pode-se favorecer o autocuidado e a educação para o exercício da cidadania. ${ }^{8}$

O saber/fazer da enfermagem é distinto do saber/agir. Esse significa ir além do prescrito, por isso está relacionado a uma ação competente, enquanto o saber/fazer é entendido como habilidade. ${ }^{7}$

Os saberes, como instrumentos indispensáveis à prática do fazer e do agir de forma eficiente e eficaz, correlacionam-se com a técnica. Essa que, muitas vezes, é irrefutável, como menciona Gadamer: "Somente profissionais podem julgar um fracasso que surge ou um erro do próprio profissional, como "erros técnicos" do médico ou do arquiteto, significa que tal área se tornou, em certo sentido, autônoma". ${ }^{1}$ Desse modo, evidencia-se que existe uma correlação entre o ser humano e o seu fazer, em que a técnica se torna ferramenta e oferece possibilidades de ampliação das habilidades humanas, o que implica em mudanças concretas sobre o mundo objetivo.

O filósofo supracitado ainda ressalta que o poder de convicção do profissional e a confiança e a colaboração do paciente representam um importante fator de cura, que pertence a uma dimensão bem diferente daquela do efeito físico-químico de medicamentos no organismo ou da intervenção cirúrgica. Assim, ele apresenta com clareza, como se agrava a relação entre a teoria (saber) e a práxis (fazer) sob as condições da ciência moderna, ensinando que a capacitação técnica prática, diminui, momentaneamente e aparentemente, a distância entre o saber geral da ciência e a decisão certa, mas que, antes, aumenta a diferença qualitativa entre o saber prático e o saber da ciência. Justamente, o fato das técnicas aplicadas serem indispensáveis, tornamse reduzidas as esperas de juízo e de experiência, das quais são tomadas decisões práticas. ${ }^{1}$ 


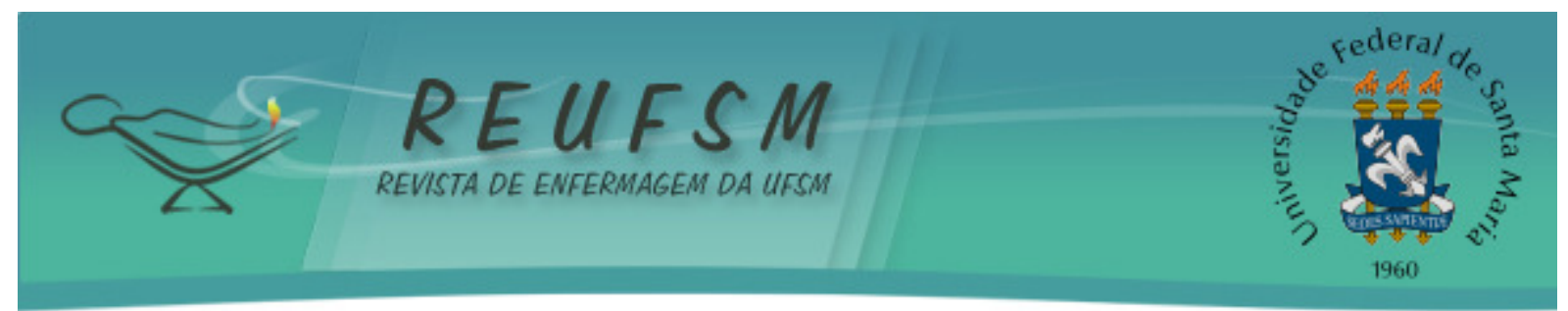

\section{Cuidado de enfermagem ao portador de ferida tumoral}

As feridas tumorais causam considerável impacto para a equipe de enfermagem, mais precisamente quando manifestadas nos estágios avançados do câncer. Esse impacto é agravado pelo sentimento de impotência do profissional diante da "cura" esperada pelo paciente. Não obstante, esse impacto poderá ser minimizado, quando o cuidado for compartilhado entre profissional e paciente, por meio de um processo dialógico entre os envolvidos, e de uma linguagem clara, concisa e objetiva, no qual, a ciência ou saber profissional será racionalizado pelo fazer ético, importando a necessidade desse paciente. ${ }^{3}$

Essas feridas podem desenvolver úlceras de aspecto visual desagradável, odores intoleráveis, produção de exsudato e sangramento incontroláveis, além de constituir uma deformidade corporal que provoca, no paciente, distúrbio da autoimagem, desgaste psicológico por sensação de desamparo, humilhação e isolamento social. Esse isolamento é justamente o que causa o impacto no profissional. Nessa situação, o cuidado paliativo torna-se a melhor indicação de cuidado aos pacientes com feridas tumorais, pois tem como objetivo o cuidar de pessoas com patologias que não respondem mais ao tratamento curativo e se caracteriza por preconizar uma postura ativa frente ao controle dos sinais e dos sintomas inerentes à fase avançada da doença, que se tornou impossível de curar. ${ }^{9}$

A finalidade desse cuidado configura-se por minimizar o sofrimento físico e psicológico, promovendo qualidade de vida para o paciente e sua família. ${ }^{3}$ Assim, o profissional de enfermagem, integrante da equipe multidisciplinar de cuidados paliativos é responsável, na maioria das vezes, pela realização de curativos e pelo cuidado desses pacientes, a partir de vivências e experiências profissionais. A enfermagem, ao se relacionar com o paciente, família e/ou comunidade, marca sua presença profissional quando expressa no cuidar um caráter dialógico. ${ }^{7}$

Essa relação dialógica dá voz, linguagem ao "ser cuidado", valorizando o sentimento, o desejo e o pensamento deste ser, possibilitando um cuidado de enfermagem regado pela subjetividade e relação social compreensiva, nas necessidades deste indivíduo portador de uma ferida tumoral, além de uma relação de confiança entre ambos. Assim, deve-se valorizar esse diálogo, escutando e consentido que o "ser cuidado" expresse seus anseios e angústias diante da sua ferida. O profissional cuidador também necessita aceitar as diferenças e não ter conceitos pré-formulados em seu cotidiano do cuidado. ${ }^{7}$

Por fim, a filosofia tem contribuição para o profissional cuidador, pelo desenvolvimento de uma consciência crítica, participativa e prática profissional humanizada, a partir dos saberes apreendidos. Possibilita um caminhar para o ser, pois pretende conhecer como o homem encontra-se vivendo alguma situação ou significando sua relação com o mundo. A fenomenologia tem contribuição para o cuidar da enfermagem, por alcançar a compreensão dos acontecimentos do cotidiano, sendo necessário que saiba imergir na subjetividade e na sua essência, sem esquecer da objetividade que o envolve. ${ }^{10}$

\section{Hermenêutica de Gadamer e o cuidado de enfermagem}

O filósofo, Hans-Georg Gadamer, considerado por pensamentos amplos, teve como idéia central dos seus escritos que todo entendimento ou ato de compreensão se processa, essencialmente, a partir do diálogo e que é mediante o estudo aprofundado sobre a realidade que adquirimos conhecimento, sendo que sua aplicabilidade prática, a práxis, ocorre por processo histórico experiencial. ${ }^{11}$

Para Gadamer, a Hermenêutica, encontra-se diante do desafio do incompreensível e, por meio desse, é trazida para o caminho do questionamento e obrigada a compreender 


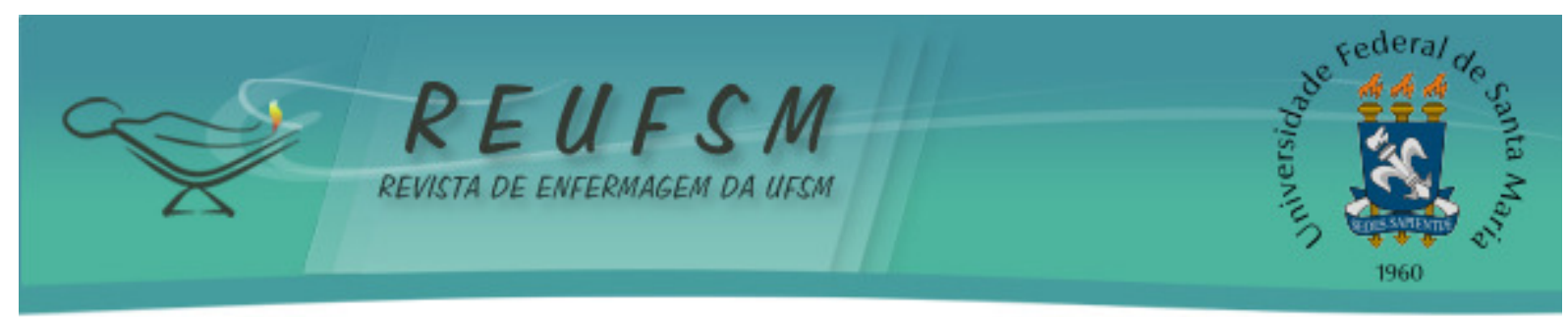

o desvelamento do sentido da palavra dita, na fala ou no texto escrito, mas que de modo singular se processa no diálogo e na construção da linguagem. ${ }^{11}$

Valorizar as contribuições hermenêuticas no modo de operar o cuidado, implica assumir que a objetualidade, inerente a qualquer ação de saúde, não deve ser o produto de um saber exclusivamente instrumental, provido por um conjunto científico-tecnológico de um profissional ou serviço que se aplica sobre um substrato passivo, o paciente ou comunidade. A objetualidade deve se produzir no encontro entre o enfermeiro, "ser que cuida", e o paciente "ser que é cuidado", que buscam soluções convenientes, sob o ponto de vista de ambos, para a prevenção, melhora da qualidade de vida e/ou diminuição dos aspectos negativos causados pela ferida tumoral. ${ }^{12}$

Sob essa perspectiva, a instrumentalidade não é suprimida, nem tampouco suprime a presença subjetiva de qualquer um dos dois lados da relação. Portadores de experiências e saberes diversos, cada qual com suas próprias sabedorias práticas e instrumentais, profissionais/serviços e pacientes/comunidade, constituem-se como sujeitos das ações de saúde, pela compreensão dos desafios práticos que os põem uns diante dos outros e pela necessidade de responderem com autonomia e responsabilidade mútua, segundo as possibilidades configuradas no contexto deste encontro. ${ }^{12}$

Assim, quanto mais o cuidado se configura como uma experiência de encontro, de trocas dialógicas verdadeiras, quanto mais se afasta de uma aplicação mecânica e unidirecional de saberes instrumentais, mais a relação entre os vários sujeitos, ali experimentada, retroalimenta seus participantes de novos saberes tecnocientíficos e práticos, contribuindo para o alcance dos objetivos dos cuidados paliativos ao paciente com ferida tumoral. ${ }^{13}$ Cabe, de qualquer forma, apontar a contribuição de alguns dispositivos no manejo técnico dessas propostas reconstrutivas, já suficientemente evidente na experiência cotidiana dos serviços de saúde.

O dispositivo evidente é o diálogo no sentido hermenêutico, por meio de produção de compartilhamentos, de familiarização e apropriação mútua do que até então era desconhecido no outro, ou apenas supostamente conhecido. Não basta, nesse caso, apenas fazer o outro falar sobre aquilo que o profissional de saúde reconhece como relevante saber. É preciso também ouvir o que o outro que demanda o cuidado, mostra ser indispensável e que ambos saibam, para que possam colocar os recursos técnicos existentes a serviço dos sucessos práticos almejados. ${ }^{12} \mathrm{Um}$ diálogo é uma interação aberta. Enquanto há diálogo, há mais o que saber, há mais o que dizer.

Gadamer, no seu trabalho em $O$ Caráter Oculto da Saúde, discute como o pensamento hermenêutico traz contribuições importantes para o campo da produção do conhecimento nas ciências da saúde. Atualmente, a ciência moderna e seus avanços biotecnológicos se apresentam em dupla face: uma face positivista, percebida pelo salto na produção e nas descobertas científicas no campo dos problemas e do cuidado em saúde, e, na outra face, a negatividade, que reduz o conhecimento em saúde a simples variáveis mensuráveis e o cuidado à pessoa humana a seus aspectos fisiopatológicos. Para ele, o importante é alcançar o equilíbrio entre a capacidade de fazer e o querer e fazer responsável, que consiste o cuidado em saúde. ${ }^{1,12}$

0 entendimento conceitual hermenêutico de Gadamer possibilitará a construção do cuidado de enfermagem ao portador de ferida tumoral, diferente do saber biomédico já estabelecido, pois permitirá uma abertura do paciente "ser que é cuidado" com o profissional "ser que cuida", permitindo a abertura de um espaço nessa assistência. 0 diálogo terapêutico proposto vai além, por suas especificidades, de ter um fim a ser alcançado e por ocorrer entre o "eu" e o "outro", mas que possuem papéis a cumprir, que são os profissionais de saúde e o ser humano vivenciando a situação de ser/estar doente. ${ }^{12}$ 


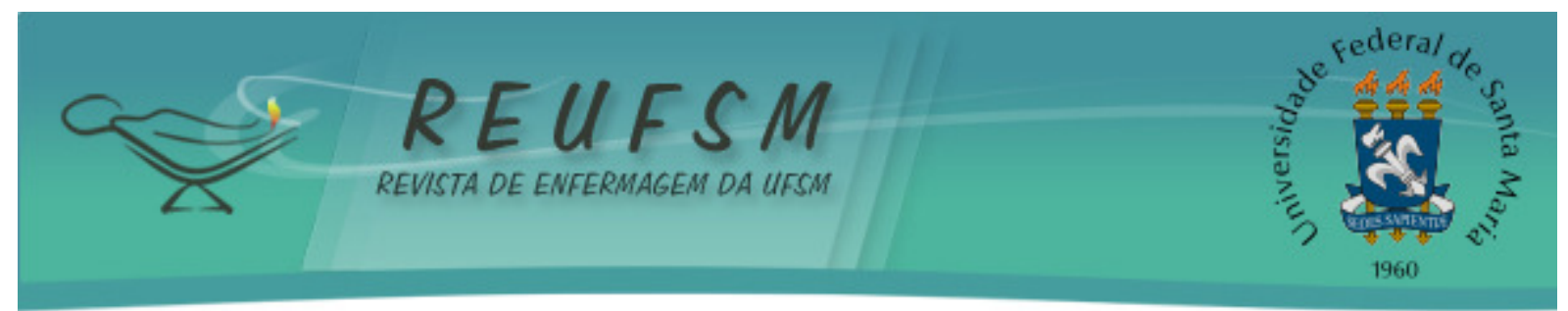

Por esse diálogo terapêutico se possibilita uma decisão compartilhada pelo cuidado mais apropriado à situação vivenciada no momento e, nesse momento, a situação que requer intervenção é o paciente portador dessa ferida que vivencia a desarmonia da saúde, expressa pela diminuição da sua qualidade de vida. O cuidado em saúde centrado no diálogo terapêutico considera o vivenciar existencial do doente diante de sua condição. $^{13}$

\section{CONSIDERAÇÕES FINAIS}

A saúde está vinculada ao "ser" do ser humano, em uma visão existencial e subjetiva da experiência humana diante do modo de vida, no qual o câncer se manifesta como perturbação. Tal situação de vivenciar essa doença e a ferida tumoral é individualizada e única, e a arte da cura vai além da dimensão biológica do ato de cuidar instrumental.

Foi possível compreender por meio desta reflexão, que um diálogo terapêutico possibilita uma decisão compartilhada pelo cuidado mais apropriado à situação vivenciada por um paciente portador de ferida tumoral. Essa, por vezes, leva ao desequilíbrio psicológico e isolamento social, relacionado às características desagradáveis da ferida e desfiguração da imagem corporal.

Evidenciou-se que o pensamento filosófico hermenêutico de Gadamer e a fundamentação filosófica do conhecimento trazem contribuições importantes para a relação de cuidado entre o enfermeiro e o paciente portador de ferida tumoral, por propor uma relação de cuidado entre esses seres conscientes, construídos de saberes científicos e empíricos, transpostos para um fazer.

Acredita-se que este estudo possa oferecer reflexões acerca do cuidado de enfermagem ao paciente portador de ferida tumoral, ampliando a compreensão da dimensão desse cuidado, pautado num pensamento hermenêutico.

\section{REFERÊNCIAS}

1. Gadamer HG. O caráter oculto da saúde. 2aa ed. Petrópolis: Vozes; 2011.

2. Caregnato RCA, Martini RMF, Lautert L. Gadamer: fundamentando uma proposta para o estudo do estresse no bloco cirúrgico. Rev Gaúcha Enferm [Internet]. 2005 [acesso em 2014 jun 16];26(2):161-7. Disponível em: http://hdl.handle.net/10183/23626.

3. Leite AC. Feridas tumorais: cuidados de enfermagem. Rev Científica HCE [Internet]. 2007 [acesso em 2014 jun 18];2(2):36-40. Disponível em: http: / /www.hce.eb.mil.br/rev/rev2007/feridastumorais.pdf.

4. Linhares AA. O raciocínio clínico do enfermeiro na avaliação de feridas em clientes com afecções oncológicas [dissertação]. Rio de Janeiro: Universidade do Estado do Rio de Janeiro, Faculdade de Enfermagem; 2010. 113p.

5. Vale EG, Pagliuca LMF, Quirino RHR. Saberes e práxis em enfermagem. Esc Anna Nery Rev Enferm. 2009;13(1):174-80.

6. Domingues TAM, Chaves EC. O conhecimento científico como valor no agir do enfermeiro. Rev Esc Enferm USP. 2005;39(N Esp):580-8.

7. Simões SMF. O significado do pensar/fazer da prática do enfermeiro: uma revisão sistemática em artigos da REBEn 1932-1971. Esc. Anna Nery Rev Enferm. 2007;11(3):50914. 


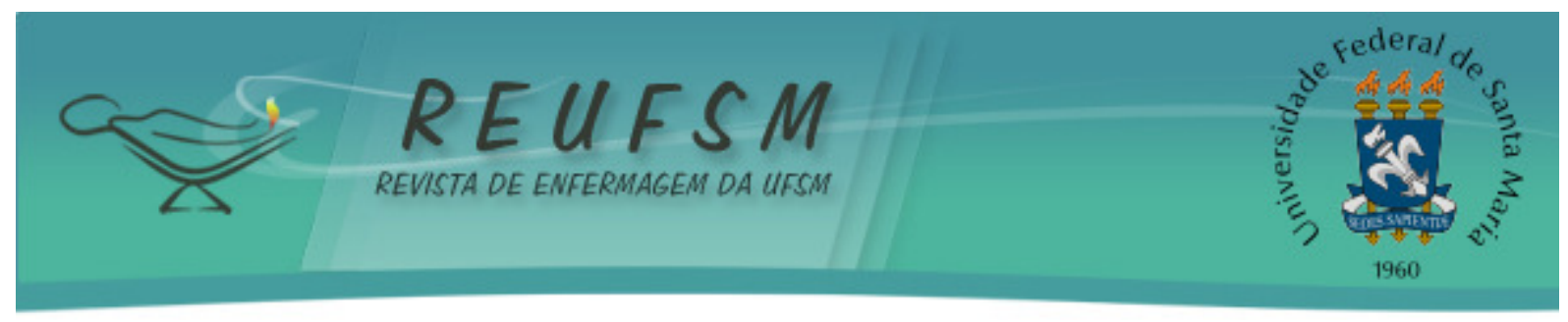

8. Martins PPS, Prado ML, Reibnitz KS. Por uma práxis de enfermagem criativa e reflexiva. Ciencia y Enfermeria. 2006;12(2):15-22.

9. Agra G, Fernandes MA, Platel ICS, Freire MEM. Cuidados paliativos ao paciente portador de ferida neoplásica: uma revisão integrativa da literatura. Rev Bras Cancerol. 2013;59(1):95-104.

10. Araújo RA, Cartaxo HGO, Almeida SMO, Abrão FMS, Almeida Filho AJ, Freitas CMSM. Contribuições da filosofia para a pesquisa em enfermagem. Esc Anna Nery. 2012;16(2):38894.

11. Araújo JL, Paz EPA, Moreira TMM. Hermenêutica e saúde: reflexões sobre o pensamento de Hans-Georg Gadamer. Rev Esc Enferm USP [Internet]. 2012 [acesso em 2014 jun 16];46(1):200-7. http://www.scielo.br/pdf/reeusp/v46n1/v46n1a27.pdf.

Disponível em:

12. Ayres JRCM. Uma concepção hermenêutica de saúde. Physis [Internet]. 2007 [acesso 2014 jun 16];17(1):43-62. Disponível em: http: / / www.scielo.br/scielo.php?script=sci_arttext\&pid=S0103-73312007000100004.

13. Firmino F, Alcântara LFF. Enfermeiras no atendimento ambulatorial a mulheres com feridas neoplásicas malignas nas mamas. Rev RENE [Internet]. 2014 mar-abr;15(2):298-307.

Data de recebimento: 29/05/2015

Data de aceite: 04/12/2015

Contato do autor responsável: Patrícia Lima Queiroz

Endereço postal: Condomínio Prado Residence, Bloco 6B, Apartamento 206, Cohama. CEP 65097-197. São Luís, Maranhão, Brasil.

E-mail: enfpatriciaqueiroz@gmail.com 